\title{
O SIGNIFICADO DO USO DE MÁSCARAS
}

\author{
THE MEANING OF MASKS
}

CASS R. SUNSTEIN ${ }^{1}$

RESUMO: Muitos incentivos são monetários e, quando instituições públicas ou privadas buscam mudar de comportamento, é natural mudar os incentivos monetários. Mas muitos outros incentivos são resultantes de significados sociais, sobre os quais as pessoas podem não deliberar, mas que podem operar como subsídios ou tributos. Em alguns momentos e lugares, por exemplo, o significado social do tabagismo tem sido positivo, aumentando o incentivo ao fumo; em outros tempos e lugares, foi negativo e, portanto, serviu para reduzir o tabagismo. No que diz respeito à segurança e à saúde, os significados sociais mudam radicalmente ao longo dos anos e podem ser drasticamente diferentes a depender do lugar. Muitas vezes, as pessoas se manifestam de acordo com os significados que lamentam ou, pelo menos, desejam que seja de outra forma. Mas é extremamente difícil para os indivíduos alterar os seus próprios conceitos. A alteração de conceitos pode advir da lei, que pode, por meio de um mandato, transformar o significado da ação em um mero: "Eu cumpro a lei", ou em algo menos brando, como: "Sou um bom cidadão". A alteração de significados sociais também pode advir de ação privada em larga escala, projetada ou promovida por "empreendedores que ressignificam", que pode transformar o significado da ação de "Eu sou um excêntrico" para "Eu cumpro meu dever cívico" ou "Eu protejo outras pessoas de danos." Às vezes, subgrupos se rebelam contra significados novos ou alterados, produzidos pela lei ou por empreendedores que ressignificam, mas geralmente esses significados permanecem e produzem mudanças substanciais.

Palavras-Chave: precauções; significado social; empreendedores que ressignificam.

${ }^{1}$ Traduzido para o português, com a autorização do autor, por Maíra Almeida, do artigo de Cass R. Sunstein, originalmente publicado no SSRN, em 08 de abril de 2020, The Meaning of Masks, produzido originalmente em língua inglesa. Maíra Almeida é Professora da graduação e pósgraduação em Direito da Universidade Estácio de Sá. Doutora e Mestra em Direito pelo Programa de Pós-Graduação em Direito da Universidade Federal do Rio de Janeiro (PPGD/UFRJ), pesquisadora visitante na Harvard Law School (2016-2017) com o apoio da Comissão Fulbright e pesquisadora do Laboratório de Estudos Teóricos e Analíticos sobre Comportamento das Instituições (LETACI). E-mail: almeida.maira.1@gmail.com.

Professor Robert Walmsley da Harvard University. Agradecimentos especiais a Sendhil Mullainathan e dois revisores anônimos pelos comentários extremamente valiosos da versão inicial. 
ABSTRACT: Many incentives are monetary, and when private or public institutions seek to change behavior, it is natural to change monetary incentives. But many other incentives are a product of social meanings, about which people may not much deliberate, but which can operate as subsidies or as taxes. In some times and places, for example the social meaning of smoking has been positive, increasing the incentive to smoke; in other times and places, it has been negative, and thus served to reduce smoking. With respect to safety and health, social meanings change radically over time, and they can be dramatically different in one place from what they are in another. Often people live in accordance with meanings that they deplore, or at least wish were otherwise. But it is exceptionally difficult for individuals to alter meanings on their own. Alteration of meanings can come from law, which may, through a mandate, transform the meaning of action into a bland, "I comply with law," or into a less bland, "I am a good citizen." Alteration of social meanings can also come from large-scale private action, engineered or promoted by "meaning entrepreneurs," who can turn the meaning of action from, "I am an oddball," to, "I do my civic duty," or, "I protect others from harm." Sometimes subgroups rebel against new or altered meanings, produced by law or meaning entrepreneurs, but often those meanings stick and produce significant change.

KEYWORDS: precautions; social meaning; meaning entrepreneurs.

No final de março de 2020, o presidente Donald Trump anunciou a recomendação de que todos os americanos usassem máscaras ou coberturas faciais para protegerem-se da propagação do coronavírus em ambientes públicos ${ }^{2}$. Ao mesmo tempo, ele disse que não seguiria essa recomendação, pessoalmente. Em suas palavras: "simplesmente não vejo presidentes, primeiros-ministros, ditadores, reis, rainhas usando máscaras quando os cumprimentos". ${ }^{3}$

Mas por que o presidente Trump não "viu"? Para responder a essa pergunta, vamos fazer outra. Suponha que você passe por um vizinho na rua ou em um supermercado e que ele esteja usando uma máscara. Se assim for, o que você acha?

Aqui estão sete possibilidades:

(1) Ele tem coronavírus.

(2) Ele está muito mais assustado do que deveria.

(3) Ele parece peculiar.

(4) Ele é uma pessoa antissocial e egoísta que não deseja ser infectado por outras pessoas, embora a probabilidade seja muito remota.

\footnotetext{
${ }^{2}$ Disponível em: https://www.cdc.gov/coronavirus/2019-ncov/prevent-getting-sick/cloth-face-cover.html. Acesso em: 20 de abril de 2020.

${ }^{3}$ Disponível em: https://www.newsweek.com/cdc-recommends-masks-trump-says-he-wont-wearone-because-he-meets-presidents-prime-ministers-1496064.
} 
(5) Ele está sendo prudente.

(6) Ele está simplesmente seguindo as recentes recomendações do governo.

(7) Ele está protegendo outras pessoas do risco que possa estar impondo a elas.

No que diz respeito às máscaras, as normas sociais variam entre e dentro das nações. Mas em muitos momentos e lugares, aqueles que usam máscaras produzem reações (1), (2), (3) ou (4). Parece claro que se as pessoas souberem que se usarem máscaras produzirão essas reações, elas estarão menos propensas a usar máscaras, mesmo se também acreditarem que usar marcas é uma coisa sensata a se fazer. Sua decisão será produto de um cálculo aproximado dos benefícios do uso de máscaras (para si e para os outros) e os custos das reações negativas que o uso de máscaras produzirá. O "efeito holofote" pode ser intensificado pela reação das outras pessoas. Se as pessoas exageram, a probabilidade de outras pessoas perceberem suas ações e se importarem com elas, os julgamentos e reações esperadas de outras pessoas podem parecer bastante expressivas em seus cálculos.

Na mesma linha, as pessoas podem não se recusar a comer carne, mesmo que seja o que elas prefeririam, se recusar a comer carne produziria um sinal social alto e indesejado. Como Red Auerbach, o grande técnico de basquete americano, costumava dizer: "Não é o que você diz, é o que as pessoas ouvem. " E se as pessoas souberem o que "elas" ouvirão, suas declarações e ações poderão mudar drasticamente.

O ponto mais importante é o de que as ações das pessoas têm "significados sociais" que funcionam como o equivalente a subsídios ou impostos sobre o comportamento (LESSING, 1995). ${ }^{4}$ Os significados sociais criam incentivos, às vezes pequenos e às vezes grandes. Os significados são um artefato de normas sociais, que podem servir a uma variedade de funções, boas ou ruins. ${ }^{5}$ Podemos não saber de onde vêm essas normas. $O$ ato de escavação histórica pode ser extremamente desafiador. Mas podemos saber qual funções as normas servem e essas funções podem ser altamente desejáveis, pois criam significados, positivos ou negativos.

Por exemplo o significado social que passa uma pessoa que fura fila no supermercado é: "Sou uma pessoa egoísta e não me importo com as outras pessoas". Por esse ser o significado social de furar fila, há uma menor probabilidade das pessoas furarem fila (ULMANN-MARGALIT, 2017). Algumas evidências preliminares sugerem que, com relação às pandemias, as pessoas são mais afetadas pela ideia de que medidas de precaução as impedirão de espalhá-las para outras

\footnotetext{
${ }^{4}$ Vide Lawrence Lessig, The Regulation of Social Meaning, U Chi L Rev, v. 62, n. 943, 1995. O brilhante ensaio de Lessig é o trabalho fundamental sobre esse tópico e eu me baseei bastante nele aqui. Esse debate também é encontrado em Cass R. Sunstein, Social Norms and Social Roles, Colum L Rev, v.96, n. 903, 1996.

${ }^{5}$ Uma visão otimista pode ser encontrada em Edna Ullmann-Margalit, The Emergence of Norms, 1976.
} 
pessoas, do que pela ideia de que essas medidas diminuirão seus riscos pessoais (JORDAN; YOELI;

RAND, 2020). Na maioria dos tempos e lugares, se o significado social da ação é: "Eu não ligo para você" ou "Não ligo para impor riscos à saúde", as pessoas terão uma menor probabilidade de se envolverem nessa ação.

No que diz respeito à segurança e à saúde, os significados sociais podem ter um efeito considerável nos resultados. Considere as normas contra a violência e os significados que incentivam a tolerância. A ideia de que "eu não vou machucá-lo, desde que você não me machuque" pode resolver o dilema de um prisioneiro (ULMANN-MARGALIT,1976). Para novas ameaças, velhos conceitos podem não ser suficientes. São exemplos as normas contra a poluição do ar e novos conceitos associados à poluição. No contexto de uma pandemia, os significados de uma ação podem mudar drasticamente. Isso pode ser necessário para salvar vidas. Antigos significados são literalmente perigosos.

Os significados sociais estão em toda parte e influenciam muito o que as pessoas fazem, mesmo que sejam consideradas parte das circunstâncias da vida e mesmo que as pessoas não pensem muito sobre seu impacto. Se você afivelou o cinto de segurança há algumas décadas, o motorista pode ter ouvido você dizer: "Você é um motorista terrível e estou com medo de que colidamos". Se você acendeu um cigarro em uma reunião de escritório em, digamos, 1965, pode ter sido visto como legal, ou sexy, ou simplesmente como normal. Se você se recusou a comer carne em um jantar em, digamos, janeiro deste ano, pode ter parecido peculiar, dependendo das normas vigentes.

Os significados sociais geralmente levam as pessoas a se envolverem em um tipo de comportamento, ou a se recusarem a se envolverem no mesmo padrão comportamental, contra o qual de outra forma seriam seus desejos. Se o significado de beber cerveja na festa do escritório se relacionar à diversão, as pessoas podem concordar em beber cerveja, mesmo que odeiem cerveja. Quando as pessoas não estão no meio de uma pandemia, elas podem querer se comunicar ocasionalmente, talvez porque tenham obrigações de cuidar de crianças. Talvez elas consigam obter a permissão do empregador para fazer isso. Mas se o significado do home office é o de que as pessoas não estão integralmente dedicadas ao seu trabalho e dando a ele a prioridade devida, elas podem decidir a voltar a trabalhar no escritório.

Devido ao poder dos significados sociais, as declarações e as ações muitas vezes sinalizam certas virtudes ou vícios, ou oferecem uma declaração de identidade social, um sentido da tribo à qual pertencemos. No contexto da pandemia de coronavírus, ficar muito próximo de outros clientes em uma mercearia tinha, em muitos lugares, um significado social claro: "Eu não me importo com sua saúde". Para os judeus, usar um kipá é obviamente uma declaração de afiliação e o seu valor será diferente entre os diferentes grupos. Há algumas décadas, o significado de chamar as mulheres de "senhorita" ou "sra" mudou abruptamente e aqueles que usavam esses termos, ou, em vez disso, "Sra.", ofereciam certos sinais sociais 
(geralmente, mas nem sempre, pretendidos). Nas universidades norte-americanas, chamar os alunos de "Sr." ou "Sra." recentemente passou a ter um novo significado social, porque muitas pessoas pensavam que fazer isso tinha conotações ingênuas ou ofensivas com relação à identidade de gênero. Quando as pessoas falam ou agem de determinada maneira, pode ser porque o significado social é como um imposto ou um subsídio, não em geral, mas com os grupos ou a comunidade em particular que mais lhes interessam.

Nesses aspectos, os significados sociais podem operar como substitutos de incentivos econômicos ou como complementos. Eles também podem avançar em direções concorrentes. Em vez de tributar ou multar as pessoas por (digamos) fumar cigarros, instituições públicas e privadas podem tentar estigmatizar o fumo e o relacionar a um significado social novo ou alterado. Como, por exemplo, tentar fazer com que o sinal de fumar demonstre indiferença à saúde dos outros. Como alternativa, um imposto sobre cigarros pode acompanhar um imposto sobre significado social. Ou uma penalidade de multa (por exemplo, no uso de drogas ilegais) pode ter que competir com um subsídio de significado social, em locais onde o uso de drogas ilegais sinaliza a independência e o desafio à autoridade (de uma maneira que as pessoas relevantes admiram).

Cabe aqui uma distinção entre motivações extrínsecas e intrínsecas. Estou enfatizando que os significados sociais criam uma motivação extrínseca: as pessoas não querem incorrer num deslize, ou mesmo nas sobrancelhas levantadas dos outros. Nos casos padrão, os significados sociais afetam o comportamento, mesmo que o agente esteja perfeitamente contente ou até ansioso para agir da maneira que eles desincentivam. Mas os significados sociais também podem penetrar na pele das pessoas e, assim, afetar sua motivação intrínseca, certamente a longo prazo e possivelmente a curto prazo. Se o lixo é geralmente considerado um ato não civil ou imprudente, ou pior do que isso, o lixo em potencial pode internalizar esse julgamento. Se flertar com um subordinado tem o significado social de discriminar ou usar pessoas, os empregadores podem não querer flertar com os subordinados. O significado social da ação pode influenciar e muitas vezes influencia os julgamentos das pessoas sobre o que é certo ou aceitável de se fazer.

É importante ressaltar que os significados sociais mudam com o tempo. Romances antigos, peças antigas e filmes antigos são às vezes chocantes ou piores, porque agora contêm significados que não continham na época. Muitas vezes, o processo de mudança acontece lentamente, mas às vezes é questão de semanas, até dias. Como ilustrações de significados alterados, considere, por exemplo, o significado da oração na escola; o significado de comentários paqueradores e sugestivos, dirigidos a uma empregada por seu empregador; o significado da posse de armas; o significado de algum tipo de apelido racial ou religioso; o significado da bandeira confederada. Às vezes, o que era um imposto de significado modesto, porque era grande, ou vice-versa. Às vezes, o próprio sinal muda: o que antes era 
um imposto se torna um subsídio ou vice-versa. Em termos do que as pessoas fazem, essas mudanças podem fazer toda a diferença.

Naturalmente, os significados sociais não são os mesmos na China e na França. Assim como não são os mesmos no Senegal, na Itália, no Japão e na Argentina. Usar um véu islâmico está associado a uma identidade específica, tem um significado particular e pode diferir de um lugar para outro. Os mal-entendidos transculturais geralmente ocorrem porque o significado da ação (por exemplo, usar certas roupas) não é o que o agente antecipa; o agente pode estar envergonhado ou consternado por ter transmitido um significado muito distante do pretendido. $O$ ponto enfaticamente vale para comportamentos relacionados à segurança e à saúde. Usar uma máscara em Pequim em 2016 teve um significado muito diferente de usar uma máscara em Londres naquele ano. Algumas declarações e ações estão associadas a culturas identificáveis. Em alguns lugares, usar uma máscara pode precipitar algum tipo de reação racista. No meio da pandemia de coronavírus, isso se tornou muito menos provável.

Quando os significados sociais mudam, o motivo pode ser a lei (LESSING,1995). O que antes era um imposto de significado social poderia ser eliminado ou mesmo transformado em subsídio. Se a lei exige que as pessoas usem cintos de segurança, o significado de usar cintos de segurança torna-se repentinamente, para muitos, "faço o que a lei diz", e não, "não confio em você para dirigir com segurança". Se a lei exige que as pessoas não discriminem com base na raça em uma comunidade que geralmente favorece a discriminação racial, o significado de não discriminar se torna: "Eu cumpro a lei", não "rejeito os valores da minha comunidade local". Quando o significado social da ação se torna a conformidade com a lei, o que antes era um imposto foi removido ou até se transformou em um subsídio.

Claro que também é verdade que em alguns momentos e lugares as violações a lei têm um significado social positivo. A conduta ilegal pode ter um efeito perverso exatamente por esse motivo. Aqueles que violam a lei podem parecer ousados, desafiadores, legais ou impressionantemente independentes. Considere o fenômeno da "reatância" (BREHN, S; BREHN, J., 1981), pelo qual as pessoas se recusam a fazer algo precisamente porque foram ordenadas ou fortemente aconselhadas a fazê-lo. A reatância é um fenômeno familiar e pode levar a comportamentos prejudiciais a si próprio ou aos outros.

Além disso, a lei pode ter uma função expressiva (MCADAMS, 2015; SUSTEIN, 1995). Ela pode dar às pessoas um senso novo e diferente do que a maioria das pessoas pensam ou do que as pessoas mais relevantes ou confiáveis pensam. Se a lei proíbe as pessoas de enviar mensagens de texto enquanto dirigem, as pessoas podem acreditar que os cidadãos geralmente pensam que enviar mensagens de texto enquanto dirigem é uma má ideia ou que agentes públicos, munidos de informações relevantes, chegaram a essa conclusão. Esses pontos ajudam a explicar o fenômeno intrigante do cumprimento sem aplicação da lei: obediência generalizada ou automática a um comando legal, mesmo quando a aplicação é 
excepcionalmente rara (KAGAN; SKOLNIK,1993). Uma razão para essa obediência é que o significado social do descumprimento pode ser insensato ou o pior tipo de desafio ao julgamento da comunidade.

Além da lei, os significados sociais podem mudar porque pessoas especialmente importantes ou um grande número de pessoas são capazes de fazê-las mudar. "Significar empreendedores" pode ser crucial aqui, alimentando mudanças em larga escala. Eles podem estar no setor privado, eles podem ser funcionários públicos, vendo as mudanças de significado como valiosas ou mesmo essenciais para os objetivos públicos. Suponha que uma campanha educacional bem financiada enfatize a importância de ter um "motorista da vez". Nesse caso, o significado de recusar-se a beber pode mudar rapidamente. Ou suponha que os vegetarianos e o vegetarianismo se tornem mais proeminentes, simplesmente porque pessoas respeitadas e admiradas dizem, com bastante destaque, que são vegetarianos. Nesse caso, o significado social do vegetarianismo pode mudar. Um imposto de significado social é removido ou talvez se torne um subsídio.

É claro que os empreendedores têm motivações diversas quanto ao significado. Alguns deles são altruístas ou, em algum sentido, santos: eles querem salvar vidas ou impedir o que consideram sérios danos sociais. Alguns são auto-interessados: eles podem querer promover um produto ou uma carreira. Alguns têm motivações econômicas ou políticas identificáveis, que respondem por seu foco particular.

Deveríamos ser capazes de ver aqui a possibilidade de múltiplos equilíbrios, dependendo de fatores aparentemente modestos, que determinam se os empreendedores significam sucesso ou fracasso. Por exemplo, um empreendedor de significado pode tentar transformar o significado social de usar o celular com a condução, de modo que não seja "o que as pessoas fazem" ou "uma conveniência" ou "meio legal", mas sim "perigoso", ou "imprudente", ou "indiferente à segurança dos outros". Sob as condições certas, o esforço transformador poderia funcionar, pelo menos se o empreendedor de significado for capaz de iniciar uma cascata social, com as pessoas certas, no momento certo, adotando visivelmente o novo significado (GRANOVETTER, 1978; SUSTEIN, 2019). Mas com pequenas variações nas condições, o que significa que o empreendedor pode falhar e parecer um tanto tolo, pelo menos se as pessoas certas não adotarem o novo significado ou se as pessoas erradas insistirem no antigo. Pequenos fatores podem fazer toda a diferença. Um novo significado pode parecer fazer parte do arco da história, em retrospectiva, ou um significado antigo e robusto pode parecer fazer parte de uma cultura arraigada, em retrospectiva. Ambas as aparências podem muito bem ser miragens. Nada era inevitável.

Em 2020, muitas nações viram inúmeras mudanças nos significados sociais, como o significado de recusar-se a apertar as mãos, de trabalhar em casa e de lavar muito bem as mãos foi virado de cabeça para baixo. Essas mudanças incidem diretamente sobre a questão das máscaras. Também em 2020, funcionários dos Centros de Controle e Prevenção de Doenças aconselharam "o uso de coberturas 
simples de tecidos para retardar a propagação do vírus e ajudar as pessoas que podem ter o vírus e que não o conhecem de transmiti-lo a outras pessoas" ${ }^{\prime \prime}$. Por motivos de saúde pública, parecia claro que as pessoas deveriam estar usando máscaras em ambientes públicos.

Se as pessoas seguem conselhos desse tipo dependerá em parte significativa do significado social de fazer isso. Se o líder de uma nação disser: "Simplesmente não vejo... Usando máscara facial", muitas pessoas se recusam a usar uma máscara facial, porque também" simplesmente não a veem ". Mas imagine, por exemplo, se o presidente Trump tivesse anunciado a recomendação enquanto usava uma máscara - ou, no mínimo, dizendo que seguiria pessoalmente a recomendação do CDC sempre que próximo a grupos de (digamos) mais de dez pessoas. Mas o que quer que os líderes nacionais façam, outros podem oferecer uma contribuição modesta para mudar o significado de usar uma máscara, simplesmente fazendo o que o CDC recomendou - e, assim, aumentando a probabilidade do uso da máscara ser visto como o que a maioria das pessoas está fazendo para serem bons cidadãos e para protegerem uns aos outros.

Mas o ponto principal é mais amplo. Em meio a uma pandemia, é extremamente importante que as medidas de segurança sejam subsidiadas e não tributadas por seus significados sociais.

\section{REFERÊNCIAS}

BREHM, Sharon; BREHM, Jack. Psychological Reactance: A Theory of Freedom and Control. Cambridge, MA: Academic Press, 1981

\section{CENTERS FOR DISEASE CONTROL AND PREVENTION. Considerations for} Wearing Cloth Face Coverings: Help Slow the Spread of COVID-19. [S. l.], 2020. Disponível em: https://www.cdc.gov/coronavirus/2019-ncov/prevent-gettingsick/cloth-face-cover.html. Acesso em: 20 de abril de 2020.

GRANOVETTER, Mark. Threshold Models of Collective Behavior. [S.l.]: Journal of the American Chemical Society, v. 83, n. 1420, 1978.

JORDAN, Jillian; YOELI, Erez; RAND, David G. Don't get it or don't spread it? Comparing self-interested versus prosocially framed COVID-19 prevention messaging. [S.l.]: PsyArXiv, 2020. Disponível em: https://psyarxiv.com/yuq7x

KAGAN, Robert; SKOLNICK, Jerome. Banning Smoking: Compliance Without Coercion. In: RABIN, Robert; SUGARMAN, Stephen (eds.). Smoking Policy: Law, Policy, and Politics. Oxford, UK: Oxford University Press, 1993.

6 Disponível em: https://www.cdc.gov/coronavirus/2019-ncov/prevent-getting-sick/cloth-facecover.html. 
LESSING, Lawrence. The Regulation of Social Meaning. [S.l.]: University of Chicago Law Review, v.62, n. 943, 1995.

MARTIN, Jeffery. CDC Recommends Masks, But Trump Says He Won't Wear One Because He Meets 'Presidents, Prime Ministers, Dictators'. [S.l.]: Newsweek. 3 de abr. de 2020. Disponível em: https://www.newsweek.com/cdc-recommendsmasks-trump-says-he-wont-wear-one-because-he-meets-presidents-primeministers-1496064

MCADAMS, Richard. The Expressive Powers of Law. Cambridge, MA: Harvard University Press, 2015

SUNSTEIN, Cass R. How Change Happens. Cambridge, MA: MIT Press, 2019

SUNSTEIN, Cass R. Social Norms and Social Roles. [S.l.]: Columbia Law Review, v. 96, n. 903, 1996.

SUNSTEIN, Cass R. On the Expressive Function of Law. [S.l.]: University of

Pennsylvania Law Review, v. 144, n. 5, 1996.

ULLMANN-MARGALIT, Edna. The Emergence of Norms. Oxford, U.K.: Oxford University Press, 1976.

ULLMANN-MARGALIT, Edna. Considerateness. In: Ullmann-Margalit, Edna. Normal Rationality. Oxford, U.K.: Oxford University Press, 2017. 